\title{
PENERAPAN E-COMMERCE PADA UMKM CENDERAMATA KERAJINAN ALIF
}

\author{
Satriadi $^{1)}$, Dani Masrianto ${ }^{2) *}$, Deri Afrizon ${ }^{3)}$, Hanifa Gustryanda ${ }^{4)}$, Seri Mulyani ${ }^{5)}$, \\ Febri Lukita ${ }^{6}$ \\ ${ }^{1)}$ Manajemen, STIE Pembangunan Tanjungpinang. email: satriadi456@ gmail.com \\ ${ }^{2)}$ Manajemen, STIE Pembangunan Tanjungpinang. email: masrianto.dani@gmail.com \\ ${ }^{3)}$ Manajemen, STIE Pembangunan Tanjungpinang. email: deriafrizon88@ gmail.com \\ ${ }^{4)}$ Manajemen, STIE Pembangunan Tanjungpinang. email: gushanifa1108@ gmail.com \\ ${ }^{5)}$ Manajemen, STIE Pembangunan Tanjungpinang. email: srimuliani0798@gmail.com \\ ${ }^{6)}$ Akuntansi, STIE Pembangunan Tanjungpinang. email: febriilukita@gmail.com
}

\begin{abstract}
ABSTRAK
Penelitian ini bertujuan untuk mengetahui respon masyarakat terhadap ecommerce, mengetahui dampak penerapan e-commerce terhadap perilaku masyrakat Kota Tanjungpinang, mengetahui tingkat kepuasan Masyrakat dalam melakukan transaksi perdagangan melalui e-commercedan mengidentifikasi faktor internal dan eksternal dalam penerapan e-commerce pada usaha kecil dan menengah. . Jenis penelitian yang digunakan kulitatif, sumber data yang digunakan yaitu sumber data primer dan sekunder. Teknik analisis yang digunakan analisis Internal Factors Analysis dan External Factors Analysis serta analisis Strengths, Weaknesses, Opportunities, dan Threats. Hasil penelitian ini menunjukkan bahwa penerapan e-commerce hampir keseluruhan telah mengenal e-commerce sebagai transaksi jual beli online dengan menggunakan teknologi dan memanfaatkan media internet yang dapat digunakan kapan saja, dalam menggunakan e-commerce kendala yang dihadapi hanya dari jaringan internet yang belum bisa terakses disuatu tempat. E-commerce banyak kemudahan yang didapatkankan, lebih efektif dan efisien serta merasakan kepuasan setelah melakukan pembelian dengan menggunakan di Tanjungpinang. Berdasarkan jumlah kekuatan dan peluang yang lebih dominan dibandingkan kelemahan dan ancaman. E-commerce menjadikan perilaku masyarakat Kota Tanjungpinang menjadi konsumtif tetapi dengan adanya e-commerce masyarakat jugadapat memanfaatkannya untuk menawarkan produknya.
\end{abstract}

Kata kunci: E-commerce, UKM, SWOT, Strategi

\begin{abstract}
This study aims to determine the public's response to e-commerce, determine the impact of the application of e-commerce on the behavior of the people of Tanjungpinang City, determine the level of public satisfaction in conducting trade transactions through e-commerce and identify internal and external factors in the application of e-commerce in small and medium enterprises. . . The type of research used is qualitative, the data sources used are primary and secondary data sources. The analysis technique used is the analysis of Internal Factors Analysis and External Factors Analysis and analysis of Strengths, Weaknesses, Opportunities, and Threats. The results of this study indicate that the application of e-commerce is almost entirely familiar with e-commerce as an online buying and selling transaction using technology and utilizing internet media that can be used at any time, in using e-commerce the constraints faced are only from the inaccessible internet network. at some place. E-commerce has many conveniences, is more effective and efficient and feels satisfaction after making a purchase using Tanjungpinang. Based on the number of strengths and opportunities that are more dominant than weaknesses and threats. E-commerce makes the behavior of the people of Tanjungpinang City consumptive, but with the existence of e-commerce, people can also use it to offer their products.
\end{abstract}

Keywords: E-commerce, UKM, SWOT, Strategy 


\section{PENDAHULUAN}

Pertumbuhan ekonomi suatu negara tidak terlepas dari kegiatan perdagangan, yang secara tidak langsung dapat mempengaruhi tigkat devisa suatu negara. Salah satu tolak ukur sebuah negara dapat dikatakan negara maju atau berkembang dapat dilihat dari pertumbuhan ekonomi melalui kegiatan perdagangan. Sebelum ditemukan internet kegiatan jual beli dilakukan secara tradisional melalui tatap muka langsung antara penjual dan pembeli. Namun seiring berjalannya waktu setelah internet ditemukan setiap negara mulai menjalankan kegiatan perdagangan menggunakan internet karena dinilai lebih efektif dan efisien. Perkembangan teknologi informasi menempatkan sistem informasi sebagai elemen penting dalam aktivitas sehari-hari untuk menjadikan sarana komunikasi dalam berbagai kegiatan salah satunya perdagangan. Salah satu tren dalam teknologi informasi adalah pemanfaatan internet. Penggunaan internet dapat digunakan untuk bertukar informasi secara elektronik untuk aplikasi strategi bisnis, seperti: penjualan, pemasaran, pembelian, serta pelayanan kepada pelanggan atau konsumen, pemanfaatan internet yang dilakukanoleh pelaku bisnis termasuk para pendiri UMKM dianggap sebagai salah satu sumber pertumbuhan ekonomi lokal (Maupa, Jusri, Taba, \& Baumassepe, 2019). Dengan adanya internet akan menjadi peluang yang sangat besar untuk mengembangkan usaha dengan berbagai kemudahan dan sangat efisien untul digunakan masyarakat sekarang. E-commerce memudahkan pelaku usaha untuk bertemu dengan konsumen di berbagai daerah bahkan memungkinkan di belahan dunia lainnya. Dalam hal ini dapat dimanfaatkan oleh pelaku usahauntuk menggunakan strategi pemasaran dengan menggunakan sarana internet yaitu $e$ commerce.

Menurut Lauden dan Laudon(Kasmi, Sari, \& Muslihudin, 2015) (pengembangan ecommerce) menyatakan e-commerce adalah proses membeli dan menjual produk-produk secara elektronik oleh konsumen dan dari perusahaan mengggunakan sistem jaringan komputer sebagai perantara transaksi bisnis. E-commerce juga merupakan sebagian dari nilai keunggulan dalam persaingan bisnis saat ini, menerapak e-commerce pada usaha sama juga dengan mempertahankan usaha tetap terus berjalan.E-commerce jugadigunakan oleh pelaku bisnis untuk melakukan strategi pemasaran, pengiriman, pelayanan, dan pembayaran pelanggan. Pemanfaatan E-Commerce juga merupakan sebagai bentuk upaya inovasi pelayanan dari pemilik usaha kecil menengah kepada para konsumen atau pelanggan mereka(Saputra, 2017). Kondisi ini telah banyak mengubah cara pandang dan gaya hidup masyarakat dalam memenuhi suatu kebutuhan dan keinginannya. Revolusi dalam bidang teknologi informasi telah mengubah perilaku bisnis dan pemasaran di lingkungan UMKM. Semakin banyak UKM yang menerapkan internet serta media sosial untuk 
berkomunikasi dengan pemasok, konsumen, dan para rekan bisnis. Transformasi pemasaran ini telah memberikan peluang bagi UKM untuk tumbuh secara dinamis dan berkesinambungan (Mumtahana, Hani Atun, Nita \& Tito, 2017)Perubahan ini juga dapat mempengaruhi konsumen dalam membeli suatu produk dan juga dapat mempengaruhi perilaku suatu organisasi untuk dapat mengembangkan bisnisnya. Perilaku konsumen dalam menerapkan e-commerce juga dapat dipengaruhi oleh kepuasan dalam melakukan pembelian melalui sehingga dapat berhubungan dengan suatu kepercayaan konsumen pelaku usaha UMKM dalam melakukan pembelian melalui e-commerce dengan kondisi seperti ini membuat peneliti ingin melakukan penelitian dengan mengambil objek yaitu UMKM Kerajinan Alif.

Kerajinan Alif merupakan sebuah usaha mandiri yang didirikan oleh warga Kampung Kelam Pagi. Meskipun daerah ini termasuk bagian terdalam dari pulau Dompak, namun tidak sedikit masyarakat dari luar daerah yang hilir mudik melewati wilayah Dompak. Di sekitarnya merupakan wilayah perkantoran Provinsi Kepulauan Riau, masyarakat sekitar biasanya memanfaatkan situasi hilir mudik tersebut untuk meningkatkan pendapatan, apalagi pulau Dompak dikenal dengan pariwisatanya. Potensi budaya dan kearifan lokal dalam pengembangan pariwisata bagi para pelaku usaha, menjadi sebuah peluang dalam meningkatkan produk kreativitas manusia yang memiliki nilai ekonomi. Salah satu upaya pengembangan keterampilan pariwisata berbasis budaya dan kearifan lokal dikemas dalam bentuk kerajinan tangan berupa cenderamata, yang dapat dijadikan sebagai pemberian, kenang-kenangan dan tanda pengingat. Cenderamata yang dihasilkan berupa lampu hias dengan ukiran diatas akrilik/kaca mika yang dihiasi dengan lampu led. Selain itu, Kerajinan Alif juga menjual beragam rak bunga terbuat dari kayu, plakat, serta souvenir berupa gantungan dari kulit Gong-gong yang diberi warna dan tulisan sesuai pesanan pelanggan.

Dalam menjalankan usahanya, pemilik Kerajinan Alif, sejak mendirikan usahanya di tahun 2018 masih menggunakan cara yang sederhana dan tradisional. Sehingga, dianggap kurang efisien untuk dapat meningkatkan kuantitas dari penjualan, termasuk juga dalam pencatatan keuangan yang masih dicampur antara pendapatan dari usaha dengan kebutuhan pribadi. Selain itu, pemasaran produk juga dilakukan dengan cara sederhana, hanya melalui ucapan dari warga ke warga, sehingga penyebaran informasi dianggap kurang luas. Hal ini terjadi akibat minimnya peralatan, serta kurangnya pengetahuan akan teknologi serta media sosial terkini.

Namun setelah beberapa tahun berjalan kerajinan Alif sendiri telah menggunakan Ecommerce sebagai alat untuk melakukan transaksi penjualan agar lebih mempermudah dalam hal memasarkan produk. Terlebih masyrakat kota Tanjungpinang merupakan 
salah satu masyarakat dengan penggunaan ecommerce terbanyak di wilayah Kepri. Oleh sebab itu peranan masyrakat untuk mengetahui produk yang di dapatkan dari kerajinan alif adalah sebagai penambahan pengguna e-commerce untuk mengetahui perkembangan e-commerce lebih dalam. Sehingga e-commerce semakin dikenal oleh masyarakat kota tanjungpinang dan menjadikan e-commerce sebagai alat dalam menunjang setiap transaksi penjualan dan pembelian. Adapun penelitian ini bertujuan untuk mengidentifikasi faktor-faktor internaldan eksternal dalam penerapan ECommerce yang dilakukan UMKM Kerajinan Alif..

\section{E-commerce}

E-commerce atau Electonical Commerce (perdagangan elektronik) adalah kegiatan jual beli barang/jasa atau transmisi dana/data melalui jaringan elektronik, terutama internet. Dengan perkembangan teknologi informasi dan software, hal ini membuat transaksi konvensional menjadi mungkin untuk dilakukan secara elektronik(Kasmi et al., 2015). Website digunakan sebagai pengganti toko offline. Website e-commerce mencakup berbagai fungsi seperti etalase produk, pemesanan online dan inventarisasi stok, untuk menjalankan fungsi utama sebagai e-commerce Software yang digunakan terpasang pada server $e$-commerce dan bekerja secara simultan dengan sistem pembayaran online untuk memproses transaksi umum (Slamet et al., 2017)ecommerce artinya melakukan bisnis melalui jaringan yang saling terhubung (interconnected networks/internet).

E-commerce seperti yang diungkapkan oleh Chandra dalam merupakan penjualan atau pembelian barang dan jasa, antara perusahaan, rumah tangga, individu, pemerintah dan masyarakat atau organisasi swasta lainnya, yang dilakukan melalui komputer pada media jaringan, serta dilihat dari prespektif yang diungkapkan oleh Maulana dalam (Arifianto \& Coiri, 2018)menjelaskan bahwa ecommerce merupakan dengan menggunakan internet dan komputer dengan browser web untuk mengenalkan, menawarkan, menjual dan membeli produk. fungsi yang dapat ditimbulkan oleh adanya ecommerce dapat dirasakan oleh pengguna Ecommerce seperti yang diungkapkan oleh Candra dalam (Ferry Duwi Kurniawan, 2014) merupakan penjualan atau pembelian barang dan jasa, antara perusahaan, rumah tangga, individu, pemerintah dan masyarakat atau organisasi swasta lainnya, yang dilakukan melalui komputer pada media jaringan, serta dilihat dari prespektif yang diungkapkan oleh Maulana (2015) menjelaskan bahwa ecommerce merupakan dengan menggunakan internet dan komputer dengan browser web untuk mengenalkan, menawarkan, menjual dan membeli produk. fungsi yang dapat ditimbulkan oleh adanya ecommerce dapat dirasakan oleh pengguna. 
Usaha Mikro, Kecil dan Menengah (Menegkop dan UKM), bahwa yang (UMKM)

Menurut UU No. 20 Tahun 2008 Pasal

3 Tentang Usaha Mikro. Kecil dan Menengah, maka yang dimaksud dengan Usaha Mikro. Kecil dan Menengah yaitu:

1. Usaha Mikro adalah Usaha Produktif milik orang perorangan dan atau badan usaha perorangan yang memenuhi kriteria Usaha Mikro sebagimana diatur dalam Undang-Undang ini.

2. Usaha Kecil adalah usaha ekonomi produktif yang berdiri sendiri, yang dilakukan oleh orang perorangan atau badan usaha yang bukan merupakan anak perusahaan atau bukan cabang perusahaan yang dimiliki, dikuasai atau menjadi bagian baik langsung maupun tidak langsung dari Usaha Menengah atau Usaha Besar yang memenuhi kriteria Usaha Kecil sebagaimana yang dimaksud dalam Undang-Undang ini.

3. Usaha Menengah adalah usaha ekonomi produktif yang berdiri sendiri, yang dilakukan oleh orang perorangan atau badan usaha yang bukan merupakan anak perusahaan atau cabang perusahan yang dimiliki, dikuasai atau menjadi bagian baik langsung maupun tidak langsung dengan Usaha Kecil atau Usaha Besar dengan jumlah kekayaan bersih atau hasil penjualan tahunan sebagaimana diatur dalam Undang-Undang ini (Ferry Duwi Kurniawan 2014).

Menurut Kementrian Menteri Negara Koperasi dan Usaha Kecil Menengah dimaksud dengan Usaha Kecil (UK), termasuk Usaha Mikro (UMI), adalah entitas usaha yang mempunyai memiliki kekayaan bersih paling banyak Rp 200.000.000, tidak termasuk tanah dan bangunan tempat usaha, dan memiliki penjualan tahunan paling banyak Rp 1.000.000.000. Sementara itu, Usaha Menengah (UM) merupakan entitas usaha milik warga negara Indonesia yang memiliki kekayaan bersih lebih besar dari Rp 200.000.000 s.d. Rp 10.000.000.000, tidak termasuk tanah dan bangunan. (Sudayanto, Ragimun, dan Rahma 2011).

\section{METODOLOGI PELAKSANAAN KEGIATAN}

\section{Jenis Penelitian}

Jenis penelitian yang digunakan pada penelitian ini yaitu dengan menggunakan jenis deskriptif kualitatif yaitu penelitian berupa kata-kata, gambar dan bukan berupa angka dalam mengumpulkan datanya dengan tujuan untuk menggambarkan kejadian yang didapat berdasarkan data dilapangan. Dalam penelitian ini peneliti menggunakan pendekatan studi kasus dan lapangan yang merupakan penelitian dengan karakteristik masalah berkaitan dengan kondisi saat ini terjadi dan latar belakang dari suatu objek mengenai fenomena untuk mengidentifikasidan strategi manajerial UMKM

\section{Jenis Data}

Jenis data yang digunakan dalam penelitian ini terdiri dari data Primer (hasil wawancara) dan data Sekunder (laporan kantor kelurahan dompak, berupa hasil 
kuesioner pada para pelaku UMKM yang telah menggunakan e-commerce)

\section{Teknik Analisis Data}

Penelitian ini menggunakan teknik analisis SWOT yang bertujuan untuk mengidentifikasi dan menganalisis faktorfaktor internal dan eksternal dari penerapan e-commerce pada UMKM Kerajinan Alif. Proses analisis data menggunakan cara mendesripsikan, menggambarkan realitas secara runtun dan selanjutnya dikelompokkan berdasarkan analisis internal dan eksternal. Analisis SWOT mampu menganalisis secara kritis mengenai pendekatan e-commerce dalam rangka untuk meningkatkan daya saing UMKM Kerajinan Alif.

\section{HASIL DAN PEMBAHASAN}

Adapun hasil identifikasi faktor internal dan faktor eksternal UMKM Kerjinan Alif serta bagaimna penerapan E-commerce dapat dilihat dari tabel SWOTdibawah ini

Tabel 1

\begin{tabular}{|c|c|}
\hline $\begin{array}{c}\text { Faktor-Faktor Internal Dan } \\
\text { Eksternal }\end{array}$ & Indikator \\
\hline $\begin{array}{l}\text { Kekuatan (Strength) } \\
\text { Internal }\end{array}$ & $\begin{array}{l}\text { - } \quad \text { Barang yang digunakan merupakan dari bahan pilihan } \\
\text { - Harga jual Reatif Murah } \\
\text { - } \text { Desain dapat disesuaikan dengan keinginan konsumen } \\
\text { - Proses pembuatan Relatif cepat }\end{array}$ \\
\hline $\begin{array}{l}\text { Kelemahan (Weakness) } \\
\text { Internal }\end{array}$ & $\begin{array}{l}\text { - Kurang pengetahuan tentang bidang penjualan online } \\
\text { - Barang yang digunakan masih menggunakan alat-alat } \\
\text { tradisional } \\
\text { - Modal yang dimiliki terbatas }\end{array}$ \\
\hline $\begin{array}{l}\text { Peluang (Opportunities) } \\
\text { Eksternal }\end{array}$ & $\begin{array}{l}\text { - Adanya dukungan dari instansi terkait yakni pihak } \\
\text { kelurahan } \\
\text { - Saingan yang bergerak dalam bidang sama sedikit } \\
\text { - Dapat menjadi usaha yang unggul dalam bidang seni }\end{array}$ \\
\hline $\begin{array}{l}\text { Ancaman (Threats) } \\
\text { Eksternal }\end{array}$ & $\begin{array}{l}\text { - Minat akan seni masyarkat kurang } \\
\text { - Adanya persaingan dari daerah lain yang menjual produk } \\
\text { yang sama }\end{array}$ \\
\hline
\end{tabular}

Setelah mengetahui faktor-faktor internal dan eksternal dari UMKM Kerajinan Alif maka tahap Selanjutnya masuk kepada tahapan analisis menggunakan Matriks SWOT

Tabel 2

\begin{tabular}{|c|c|c|}
\hline & 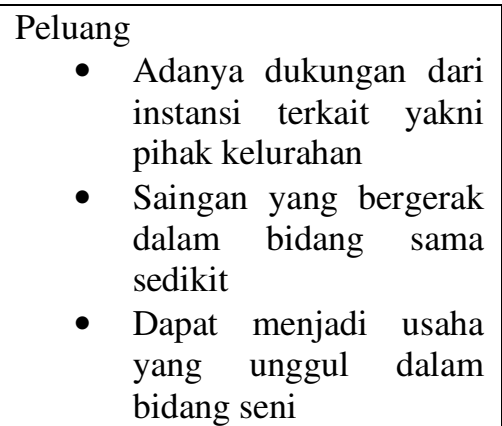 & $\begin{array}{l}\text { Ancaman } \\
\text { - } \text { Minat akan seni } \\
\text { masyarkat kurang } \\
\text { - Adanya persaingan } \\
\text { dari daerah lain yang } \\
\text { menjual produk yang } \\
\text { sama }\end{array}$ \\
\hline 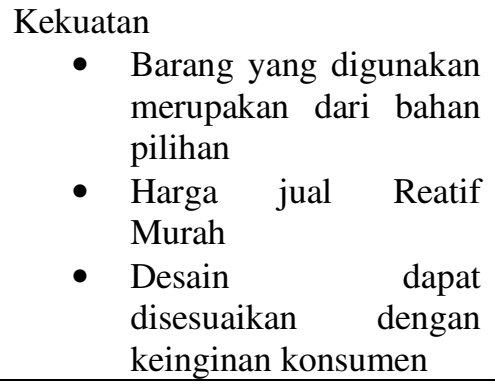 & 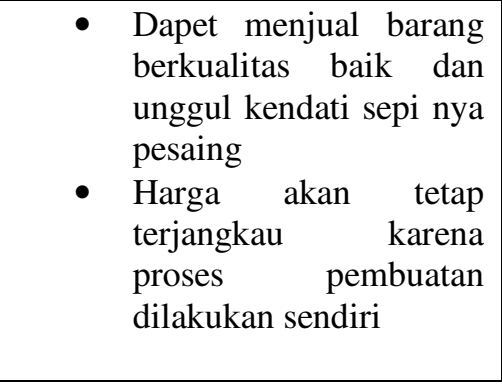 & 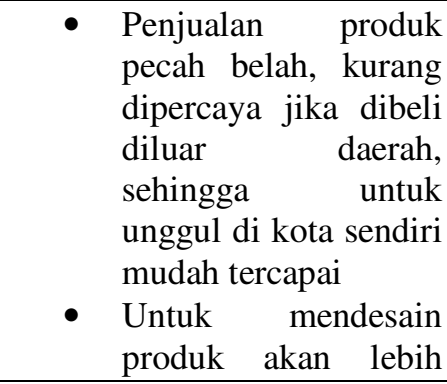 \\
\hline
\end{tabular}




\begin{tabular}{|c|c|c|}
\hline $\begin{array}{ll}\text { - Proses pembuatan } \\
\text { Relatif cepat }\end{array}$ & & $\begin{array}{l}\text { mudah jika bertatap } \\
\text { muka. }\end{array}$ \\
\hline $\begin{array}{l}\text { Kelemahan } \\
\text { - Kurang pengetahuan } \\
\text { tentang bidang } \\
\text { penjualan online } \\
\text { - } \text { Barang yang digunakan } \\
\text { masih menggunakan } \\
\text { alat-alat tradisional } \\
\text { - Modal yang dimiliki } \\
\text { terbatas }\end{array}$ & $\begin{array}{l}\text { - Dapat menjual barang } \\
\text { barang yang dianggap } \\
\text { mumpuni atau tidak } \\
\text { membutuhkan modal } \\
\text { besar } \\
\text { - Belajar dapat dilakukan } \\
\text { dimana saja dan kapan } \\
\text { saja. }\end{array}$ & 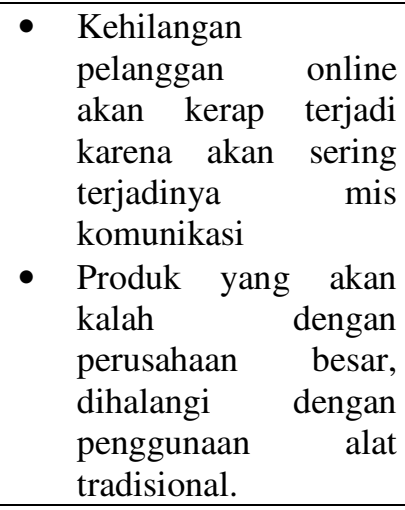 \\
\hline
\end{tabular}

Hasil analisis pada tabel 2 menunjukkan bahwa strategi yang dapat diterapkan oleh pelaku UMKM Kerajinan Alif di Tanjungpinang yaitu strategi strengthopportunity (berupa keunggulan bersaing) sebagai kombinasi antara peluang dan kekuatan yang dimiliki UMKM. Posisi UMKM merupakan situasi yang sangat menguntungkan karena tingkat kekuatan dan peluang yang lebih besar dibandingkan kelemahan dan ancaman. Kebijakan yang tepat untuk UMKM yaitu kebijakan pertumbuhan yang agresif. Penjabaran strategi strength-opportunity yaitu: peningkatan kerjasama dengan pemerintah dalam bentuk pelatihan dan penyuluhan mengenai e-commerce, dukungan teknis dan bantuan lainnya; dan (b) dukungan pemerintah berupa modal kerja untuk meningkatkan kualitas adopsi e-commerce

\section{KESIMPULAN}

Dengan perkembangan teknologi informasi dan software, hal ini membuat transaksi konvensional menjadi mungkin untuk dilakukan secara elektronik. Website e-commerce mencakup berbagai fungsi seperti etalase produk, pemesanan online dan inventarisasi stok, untuk menjalankan fungsi utama sebagai e-commerce Software yang digunakan terpasang pada server e-commerce dan bekerja secara simultan dengan sistem pembayaran online untuk memproses transaksi umum e-commerce artinya melakukan bisnis melalui jaringan yang saling terhubung (interconnected networks/internet). Fungsi yang dapat ditimbulkan oleh adanya e-commerce dapat dirasakan oleh pengguna e-commerce seperti yang merupakan penjualan atau pembelian barang dan jasa, antara perusahaan, rumah tangga, individu, pemerintah dan masyarakat atau organisasi swasta lainnya, yang dilakukan melalui komputer pada media jaringan, e-commerce merupakan dengan menggunakan internet dan komputer dengan browser web untuk mengenalkan, menawarkan, menjual dan membeli produk. Jenis penelitian yang digunakan pada penelitian ini yaitu dengan menggunakan jenis deskriptif kualitatif yaitu penelitian 
berupa kata-kata, gambar dan bukan berupa angka dalam mengumpulkan datanya dengan tujuan untuk menggambarkan kejadian yang didapat berdasarkan data dilapangan. Penelitian ini menggunakan teknik analisis SWOT yang bertujuan untuk mengidentifikasi dan menganalisis faktorfaktor internal dan eksternal dari penerapan e-commerce pada UMKM Kerajinan Alif. Hasil analisis pada tabel 2 menunjukkan bahwa strategi yang dapat diterapkan oleh pelaku UMKM Kerajinan Alif di Tanjungpinang yaitu strategi strengthopportunity (berupa keunggulan bersaing) sebagai kombinasi antara peluang dan kekuatan yang dimiliki UMKM. Kebijakan yang tepat untuk UMKM yaitu kebijakan pertumbuhan yang agresif.

\section{DAFTAR PUSTAKA}

Arifianto, E. Y., \& Coiri, M. (2018). Pemanfaatan E-Commerce Dalam Pebelajaran Manajemen Usaha Kecil Dan Menengah. Jurnal Komunikasi Pendidikan, 2(1), 77. https://doi.org/10.32585/jkp.v2i1.67

Ferry Duwi Kurniawan, L. F. (2014). Pemberdayaan Usaha Mikro Kecil dan Menengah (UMKM) Dalam Penanggulangan Kemiskinan. JKMP (Jurnal Kebijakan Dan Manajemen Publik) 2, 2, 165. https://doi.org/10.21070/jkmp.v2i2.436

Kasmi, W. S., Sari, N. Y., \& Muslihudin, M. (2015). Pengembangan Electronic Commerce dalam Proses Meningkatkan UKM pada Dekranasda Kabupaten Pringsewu. EXPERT: Jurnal Manajemen Sistem Informasi Dan Teknologi, 5(2). https://doi.org/10.36448/jmsit.v5i2.722

Maupa, H., Jusri, Taba, I. M., \& Baumassepe, A. N. (2019). Penerapan e-commerce pada usaha kecil dan menengah di sulawesi selatan. 6014, 106-112.

Mumtahana, Hani Atun, Nita, S., \& Tito, A. W. (2017). khazanah informatika Pemanfaatan Web E-Commerce untuk Meningkatkan Strategi Pemasaran. Pemanfaatan Web E-Commerce Untuk Meningkatkan Strategi Pemasaran, 3(1), 6-15. Retrieved from http://journals.ums.ac.id/index.php/khif/ article/view/3309/2784

Saputra, A. (2017). Analisis dan rekomendasi strategi e-commerce pada usaha kecil menengah batik sokaraja. Jurnal Pro B Isnis, 10(1), 19-35.

Slamet, R., Nainggolan, B., Roessobiyatno, R., Ramdani, H., Hendriyanto, A., \& Ilma, L. L. (2017). Strategi Pengembangan Ukm Digital Dalam Menghadapi Era Pasar Bebas. Jurnal Manajemen Indonesia, 16(2), 136. https://doi.org/10.25124/jmi.v16i2.319

Sudayanto, Ragimun, dan Rahma, R. (2011). Starategi Pemberdayaan UMKM Menghadapi Pasar Bebas ASEAN. Universitas Negeri Jember, 1(UMKM menghadapi pasar bebas ASEAN), 1 .

Arifianto, E. Y., \& Coiri, M. (2018). Pemanfaatan E-Commerce Dalam Pebelajaran Manajemen Usaha Kecil Dan Menengah. Jurnal Komunikasi Pendidikan, 2(1), 77. https://doi.org/10.32585/jkp.v2i1.67

Ferry Duwi Kurniawan, L. F. (2014). Pemberdayaan Usaha Mikro Kecil dan Menengah (UMKM) Dalam Penanggulangan Kemiskinan. JKMP (Jurnal Kebijakan Dan Manajemen Publik) 2, 2, 165. https://doi.org/10.21070/jkmp.v2i2.436

Kasmi, W. S., Sari, N. Y., \& Muslihudin, M. (2015). Pengembangan Electronic Commerce dalam Proses Meningkatkan UKM pada Dekranasda Kabupaten Pringsewu. EXPERT: Jurnal Manajemen Sistem Informasi Dan Teknologi, 5(2). https://doi.org/10.36448/jmsit.v5i2.722

Maupa, H., Jusri, Taba, I. M., \& Baumassepe, A. N. (2019). Penerapan e-commerce pada usaha kecil dan 
menengah di sulawesi selatan. 6014, 106-112.

Mumtahana, Hani Atun, Nita, S., \& Tito, A. W. (2017). khazanah informatika Pemanfaatan Web E-Commerce untuk Meningkatkan Strategi Pemasaran. Pemanfaatan Web E-Commerce Untuk Meningkatkan Strategi Pemasaran, 3(1), 6-15. Retrieved from http://journals.ums.ac.id/index.php/khif/ article/view/3309/2784

Saputra, A. (2017). Analisis dan rekomendasi strategi e-commerce pada usaha kecil menengah batik sokaraja. Jurnal Pro B
Isnis, 10(1), 19-35.

Slamet, R., Nainggolan, B., Roessobiyatno, R., Ramdani, H., Hendriyanto, A., \& Ilma, L. L. (2017). Strategi Pengembangan Ukm Digital Dalam Menghadapi Era Pasar Bebas. Jurnal Manajemen Indonesia, 16(2), 136. https://doi.org/10.25124/jmi.v16i2.319

Sudayanto, Ragimun, dan Rahma, R. (2011). Starategi Pemberdayaan UMKM Menghadapi Pasar Bebas ASEAN. Universitas Negeri Jember, 1(UMKM menghadapi pasar bebas ASEAN), 1. 